\title{
Gigitiruan jembatan adesif sebagai perawatan alternatif pada kasus kehilangan satu gigi \\ Adhesive bridge as alternative treatment to replace one missing teeth
}

\author{
${ }^{1}$ Christie Rizki, ${ }^{2}$ Deddy Firman, ${ }^{2}$ Aprillia Adenan \\ ${ }^{1}$ PPDGS Prostodonsia \\ ${ }^{2}$ Bagian Prostodonsia \\ Fakultas Kedokteran Gigi Universitas Padjadjaran \\ Bandung, Indonesia
}

\begin{abstract}
Adhesive bridge is a fixed partial denture that consisted of pontic and cast metal framework retainer that cemented to abutment teeth by means of adhesive cement, used acid etch technique. Adhesive bridge can be used to replace one or two anterior or posterior teeth. This case report focused on the making of adhesive bridge in anterior and posterior single missing tooth. By minimal preparation and unanesthesied teeth, patient satisfaction could be achieved. Treatment should be done as patient needed with the adequate clinical technique and specific material manipulation.
\end{abstract}

Key words: adhesive bridge, acid etch, minimal preparation

\begin{abstract}
ABSTRAK
Gigitiruan jembatan (GTJ) adesif adalah suatu gigitiruan sebagian cekat yang mempunyai komponen pontik dan retainer dari logam non mulia yang dilekatkan pada gigi penyangga dengan perantaraan bahan adesif dengan menggunakan teknik etsa asam. Gigitiruan adesif ini dapat digunakan untuk mengganti satu sampai dua gigi baik di anterior maupun posterior dengan persyaratan tertentu. Makalah laporan kasus ini memuat pembuatan GTJ adesif pada dua kasus, kehilangan satu gigi di regio anterior, dan kehilangan satu gigi di regio posterior. Preparasi yang minimal dan tidak memerlukan anestesi cukup memberikan kepuasan bagi pasien. Perawatan harus dilakukan sesuai dengan keinginan pasien dengan pemahaman tentang teknik klinis yang tepat dan manipulasi bahan yang khusus.

Kata kunci: gigitiruan jembatan adesif, etsa asam, preparasi minimal
\end{abstract}

Koresponden: Christie Rizki, E-mail: christie.rizki@ yahoo.com

\section{PENDAHULUAN}

Gigitiruan jembatan (GTJ) adalah suatu jenis gigitiruan sebagian yang dilekatkan secara tetap pada satu atau lebih gigi penyangga, dan mengganti satu atau lebih dari satu gigi yang hilang. ${ }^{+}$Jenis GTJ ini meliputi komponen pontik dan retainer dari bahan logam non mulia yang dihubungkan secara permanen pada gigi penyangga dengan perantaraan bahan adesif serta tetap menggunakan teknik etsa asam. $^{2}$

Tindakan preparasi gigi pada pembuatan GTJ konvensional umumnya berimplikasi pada banyak kehilangan struktur sehat gigi; sebagai alternatif maka dikembangkanlah suatu teknik pembuatan gigitiruan sebagian cekat yang dilekatkan dengan ikatan kimia, dengan melibatkan sedikit atau tanpa pembuangan permukaan email jaringan gigi yang menjadi sandaran, yang disebut sebagai GTJ adesif. Dengan pengambilan jaringan permukaan gigi yang minimal atau tidak sama sekali, memungkinkan penggunaan adesif pada penderita usia muda di bawah 17 tahun yang kehilangan satu sampai dua gigi alami dalam satu lengkung rahang. ${ }^{2}$ Pada perkembangannya, GTJ adesif selanjutnya sering pula disebut sebagai resin-bonded fixed partial prostheses. $^{3}$

Gigitiruan adesif ini terdiri dari satu atau dua pontik yang didukung oleh retainer logam tipis yang diletakkan di sebelah lingual dan proksimal pada gigi sandaran. Pelekatan GTJ adesif ini tergantung antara lain pada pelekatan adesif antara email yang dietsa dan logam antara yang telah diberi retensi. ${ }^{3}$

Beberapa keuntungan dari GTJ adesif, yaitu pembuangan struktur gigi yang minimal, terbatas pada email, tidak terjadi trauma pada pulpa, tidak selalu memerlukan tindakan anestesi, preparasi supragingival, teknik pencetakannya lebih mudah, biasanya tidak memerlukan restorasi sementara, waktu kunjungannya biasanya lebih sedikit, dan apabila GTJ adesif terlepas dari gigi sandaran dapat dilekatkan kembali. ${ }^{2,3}$ Dengan demikian tidak lagi diperlukan banyak preparasi gigi penyangga yang sampai melibatkan dentin sehingga preparasi relatif tidak akan menyulitkan pasien karena tidak lagi menimbulkan banyak trauma. ${ }^{4}$

Selain keuntungan, terdapat juga beberapa kekurangan dari GTJ adesif, yaitu tidak dapat 
dibuat untuk GTJ yang panjang, prosedur pelekatan bonding yang lebih sulit jika dibandingkan GTJ konvensional, penggunaan asam untuk mengetsa mengharuskan pekerjaan yang hati-hati, koreksi ruangan sangat sulit, dan diperlukan susunan gigi penyangga yang baik. ${ }^{2,3}$

Indikasi yang tepat merupakan hal yang sangat penting untuk menentukan keberhasilan perawatan edentulus dengan menggunakan gigitiruan adesif. Indikasi pembuatan GTJ adesif, yaitu GTJ pendek yang menggantikan satu sampai dua gigi anterior maupun posterior yang hilang, gigi penyangga harus kokoh dan tidak goyah, gigitan yang ringan atau terbuka merupakan kasus yang ideal, tidak terdapat kebiasaan buruk seperti bruxism, gigi penyangga menyediakan struktur gigi yang cukup, tidak terdapat defek pada email, pasien mempunyai keinginan dan respon yang baik, dan kesehatan serta kebersihan mulut dan gigi yang baik. Di samping itu GTJ adesif dapat dibuat pada pasien muda, sedangkan GTJ konvensional merupakan kontraindikasi. ${ }^{2,3,5}$

Gigitiruan adesif merupakan kontraindikasi pada keadaan daerah tidak bergigi yang panjang, kebiasaan parafungsional, gigi penyangga terdapat kerusakan yang luas, gigi penyangga tipis, gigi penyangga tidak kokoh, overlap vertikal yang dalam, pasien yang menderita alergi nikel, dan jika tidak tersedia kualitas pelayanan laboratorium yang memadai. ${ }^{2,3,5}$

Pada artikel ini dipaparkan dua kasus, masingmasing satu kehilangan satu gigi anterior dan satu kehilangan gigi posterior yang dirawat dengan pembuatan gigitiruan jembatan adesif.

\section{KASUS}

Pasien 1

Seorang wanita berumur 35 tahun datang ke Klinik Spesialis Prostodonsia RSGM Fakultas
Kedokteran Gigi Universitas Padjadjaran, dengan maksud ingin dibuatkan gigitiruan pada rahang atas karena mengganggu penampilan. Setelah dilakukan pemeriksaan di dalam mulut, pasien kehilangan gigi 23 (gambar 1). Setelah dilakukan foto ronsen pada gigi yang akan dipakai sebagai penyangga, gigi 22 dan 24 memenuhi syarat sebagai gigi penyangga.

\section{Pasien 2}

Seorang pria berumur 35 tahun datang ke Klinik Spesialis Prostodonsia RSGM Fakultas Kedokteran Gigi Universitas Padjadjaran, dengan maksud ingin dibuatkan gigitiruan pada rahang atas karena mengganggu penampilan dan pengunyahan. Setelah dilakukan pemeriksaan di dalam mulut, pasien kehilangan gigi 24 (gambar 2). Gambaran foto ronsen menunjukkan gigi 23 dan 25 memenuhi syarat sebagai gigi penyangga.

\section{Rencana perawatan}

Ada beberapa solusi yang dipertimbangkan pada pasien 1 dan pasien 2, yaitu pembuatan gigitiruan sebagian lepasan satu sisi pada rahang atas, pembuatan GTJ konvensional pada rahang atas, pembuatan GTJ adesif anterior pada pasien 1 dan pembuatan GTJ adesif posterior pada pasien 2, dan implan juga ditawarkan ke pasien sebagai suatu alternatif. Setelah didiskusikan bersama pasien, dan mempertimbangkan faktor biaya, baik pasien 1 maupun pasien 2 memilih pembuatan GTJ adesif pada rahang atas.

\section{PENATALAKSANAAN}

Prosedur kerja pembuatan GTJ adesif,meliputi pencetakan rahang atas dan rahang bawah dengan bahan cetak alginat untuk pembuatan model studi. Selanjutnya pada model tersebut dibuat disain preparasi gigi penyangga pada gigi 22 dan 24 pada
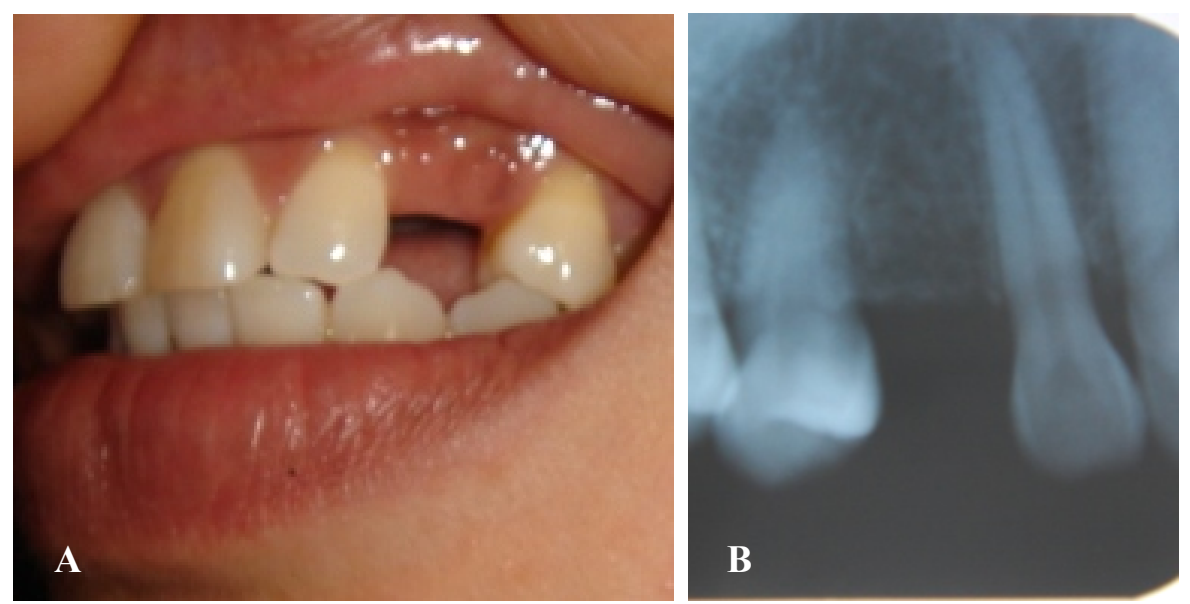

Gambar 1 Foto klinis (A) dan foto ronsen (B) pasien 1 sebelum perawatan 

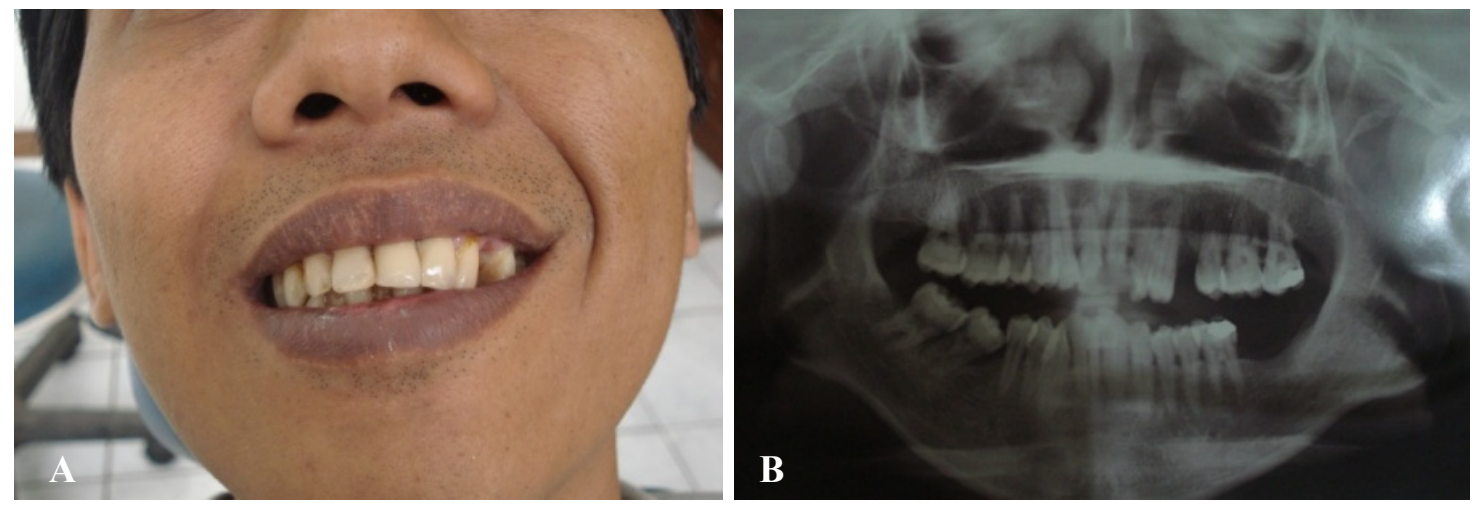

Gambar 2 Foto klinis (A) dan foto ronsen (B) pasien 2 sebelum perawatan
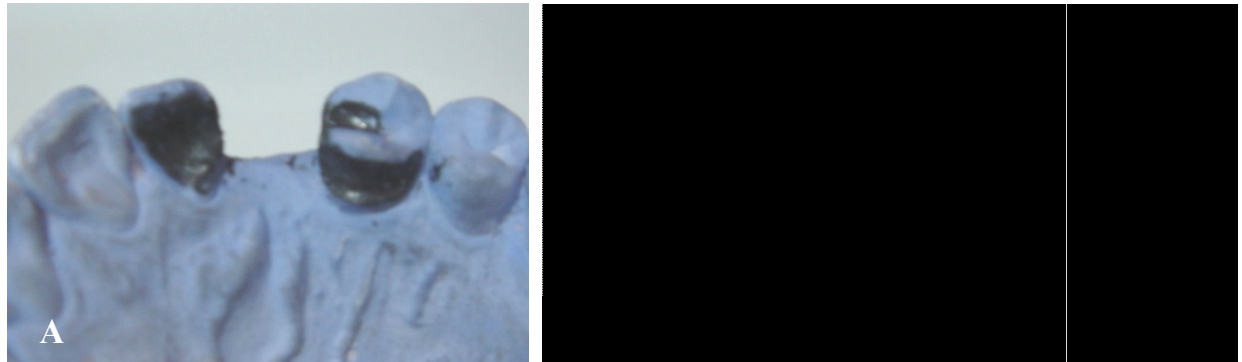

Gambar 3A Disain kerangka logam GTJ adesif anterior, B disain kerangka logam GTJ adesif posterior.

pasien 1 (gambar 3A) dan pada pasien 2 membuat disain preparasi gigi penyangga pada gigi 23 dan 25 (gambar 3B).

Disain GTJ adesif anterior meliputi bagian retentif retainer (sayap) dibuat meluas ke bagian mesial dan distal pada gigi 22 dan 24. Pembuatan rest singulum pada gigi 22 dan rest oklusal pada permukaan oklusal gigi 24. Area konektor, daerah retensi, peliputan proksimal, ketebalan kerangka logam, preparasi gigi sandaran di bagian palatinal gigi 22 dan 24, membebaskan oklusi di bagian palatinal untuk menghilangkan kontak, menyiapkan arah insersi GTJ arah insiso- atau oklusogingival, dilakukan pengurangan permukaan proksimal pada daerah tidak bergigi, pengurangan kecembungan gigi membentuk akhiran chamfer supragingival. Bagian pontik pada gigi 23 dibuat dengan disain akhiran modifikasi ridge-lap.

Disain GTJ adesif posterior meliputi gigi 23 dilakukan pengurangan daerah proksimal pada daerah tidak bergigi untuk arah insersi masuk, pembuatan rest singulum, pembentukan akhiran berbentuk chamfer supragingival. Sedangkan pada gigi 25 dilakukan pengurangan kontur proksimal di daerah yang tidak bergigi untuk arah insersi serta perluasan ke arah bukal, pengurangan bagian palatal,pembentukan rest oklusal, dan pembentukan akhiran berbentuk chamfer supragingival. Bagian pontik pada gigi 24 dibuat dengan disain akhiran modifikasi ridge-lap.
Setelah tahapan preparasi selesai sesuai disain, kemudian dilakukan pencetakan double impression dengan bahan cetak elastomer untuk pembuatan model kerja.

Untuk pengerjaan gigitiruan di laboratorium, diinstruksikan kerangka logam/sayap retainer di bagian dalam permukaan berbentuk anyaman (cast mest) pada gigi penyangga 22, 24 untuk GTJ adesif anterior rahang atas dan pada gigi penyangga 23 , 25 untuk GTJ adesif posterior rahang atas. Setelah rangka siap, dilakukan uji coba kerangka logam GTJ adesif (gambar 4), kemudian uji coba GTJ adesif porselen pada model (gambar 5). Setelah rangkanya cocok, diperiksa oklusinya lalu di-glaze, dan dilakukan pemasangan GTJ adesif (gambar 6 dan 7).

Sebelum prosedur penyemenan, permukaan gigi penyangga 22,24 pada GTJ adesif anterior dan permukaan gigi penyangga 23,25 pada GTJ adesif posterior yang akan dietsa dibersihkan dengan pumis dan pasta profilaksis lalu dipoles, kemudian dikeringkan, lalu diisolasi. Aplikasi asam fosfat pada permukaan email selama 30 detik, kemudian gigi disemprot dengan air sampai bersih dari bahan etsa dalam waktu selama 10-30 detik,lalu keringkan dengan udara. Aplikasi bahan bonding primer pada permukaan dalam sayap retainer, dan pada gigi penyangga aplikasi bonding agent lalu disinari. Aduk semen adesif, aplikasikan pada permukaan dalam sayap retainer dan gigi penyangga. 
Setelah itu GTJ adesif dipasangkan pada gigi penyangga sesuai arah pemasangan dan difiksasi pada tempatnya dengan menggunakan jari tangan. Kelebihan semen dibuang lalu dilakukan penyinaran dari arah tepi restorasi dan pada gigi penyangga, dilakukan pemeriksaan kembali oklusi dan stabilisasinya.

Instruksikan kepada pasien supaya GTJ bertahan lama tentang cara pemeliharaan kesehatan dan kebersihan gigi dan jaringan sekitarnya, kemungkinan terlepasnya pelekatan GTJ akibat pengunyahan makanan yang terlalu keras dan kebiasaan buruk seperti menggigit benda keras diantara gigi harus dihindari. Agar lapisan estetik tidak cepat berubah warnanya, sebaiknya pasien menghindari atau mengurangi konsumsi rokok, kopi dan alkohol. Apabila dirasakan ada kelainan pada GTJ dan jaringan pendukung gigi sebaiknya pasien segera memeriksakannya kembali. Pasien sebaiknya diminta untuk kontrol kembali 1 minggu setelah pemasangan, 1 bulan, 3 bulan dan setiap 6 bulan sekali. $^{2}$

\section{PEMBAHASAN}

Sejalan dengan kemajuan perkembangan ilmu Prostodonsia, dikembangkan teknik pembuatan gigitiruan sebagian cekat yang melibatkan sedikit atau tanpa pembuangan jaringan gigi penyangga dan biasanya tidak memerlukan anestesi. ${ }^{3,6}$ Teknik prostodontik cekat konvensional secara umum kontraindikasi untuk pasien muda karena masih luasnya kamar pulpa. Panjang mahkota klinis yang signifikan diperlukan untuk retensi maksimal dan bentuk resistensi. Prinsip yang selalu digarisbawahi untuk restorasi gigitiruan cekat resin-retained adalah penting untuk menutupi permukaan email sebanyak mungkin selama oklusi, estetik, dan kesehatan jaringan periodontal tidak terganggu. ${ }^{3}$

Preparasi email terdiri dari pembebasan daerah
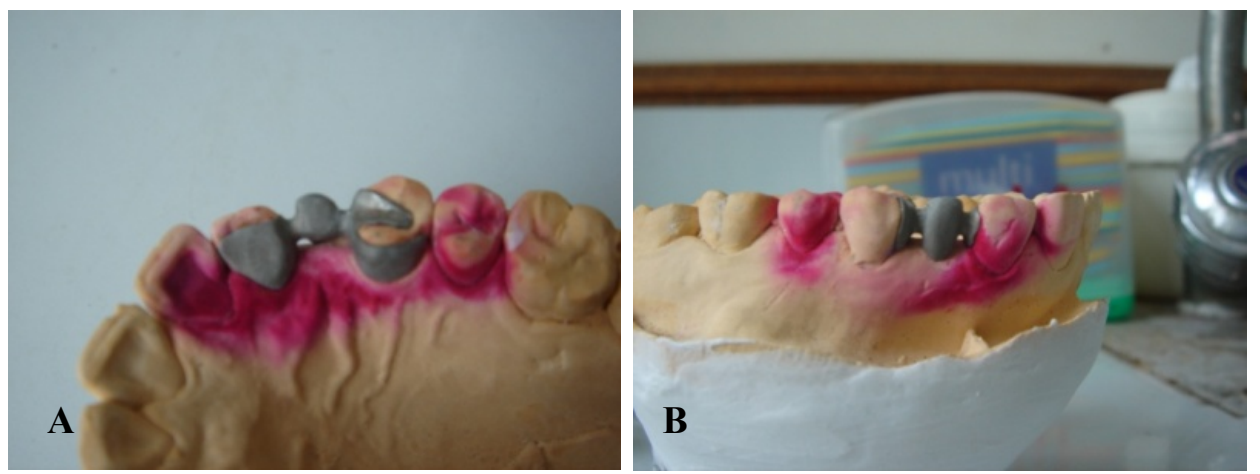

Gambar 4 Uji coba kerangka logam pada model kerja; A aspek fasial, B aspek palatinal
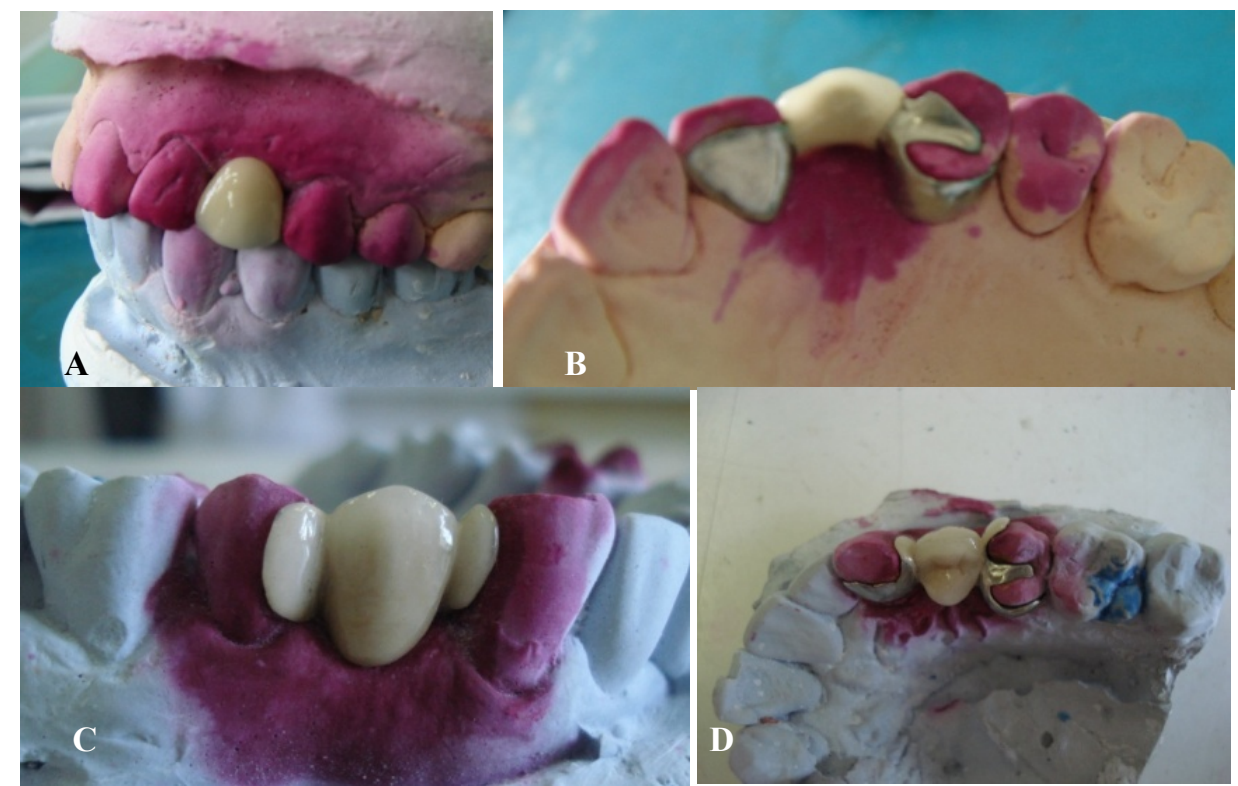

Gambar 5 Uji coba GTJ adesif porselen anterior RA pada model; A tampak fasial, B tampak palatal. Uji coba GTJ adesif porselen posterior RA pada model; A tampak bukal, B tampak oklusal. 


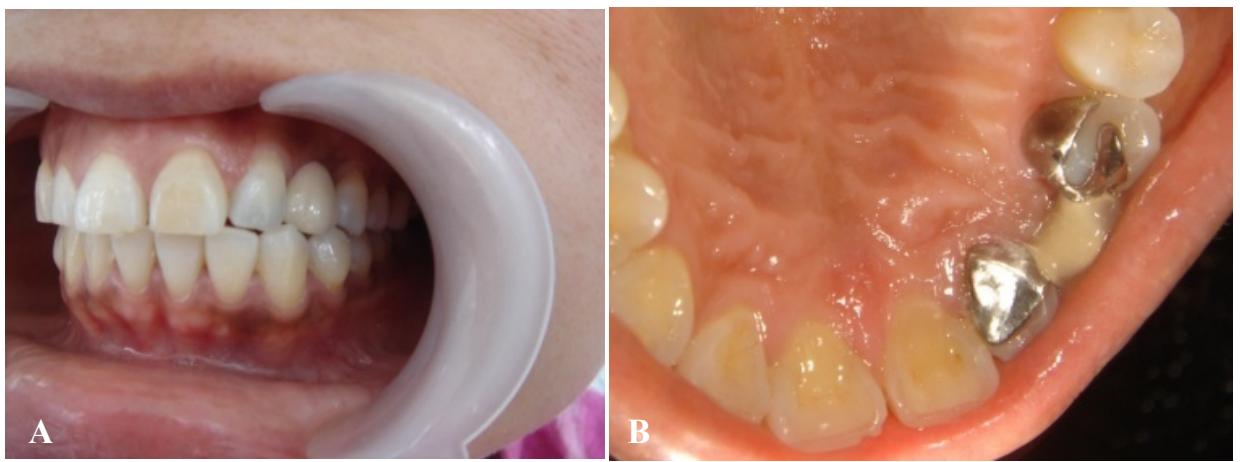

Gambar 6 Gigitiruan jembatan adesif anterior RA yang sudah disemntasi; tampak A labial dan $\mathbf{B}$ palatinal.
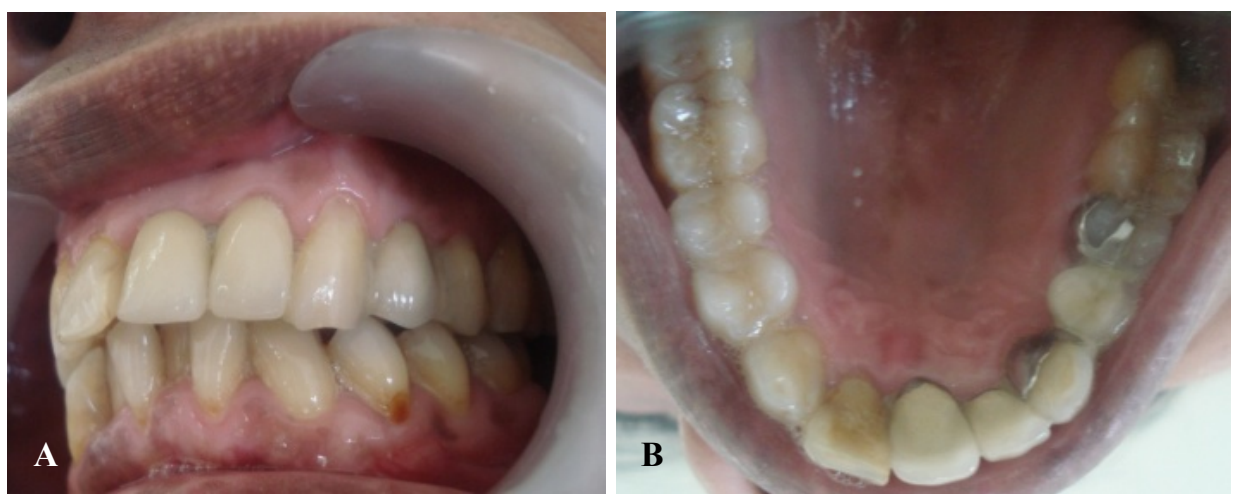

Gambar 7 Gigitiruan jembatan adesif posterior RA yang sudah disemntasi tampak A bukal, dan B palatinal.

oklusal, penempatan rest oklusal atau singulum, menurunkan tinggi kontur lingual dan proksimal, dan menciptakan perluasan rangka ke proksimal. Kerangka harus ditempatkan arah oklusogingival dan tidak boleh ada pergeseran fasiolingual. ${ }^{3}$

Tiga prinsip dasar untuk mencapai hasil yang baik dengan gigitiruan cekat resin-retained adalah pemilihan pasien yang tepat, modifikasi email dan disain kerangka logam yang baik. ${ }^{3}$

Pada kasus ini pasien 1 kehilangan gigi 23 dan pasien juga tidak menghendaki pembuatan gigitiruan lepasan dan juga tidak menghendaki pengasahan gigi yang banyak. Oleh karena itu dibuatkan GTJ adesif anterior untuk menggantikan kehilangan gigi 23, sedangkan gigi penyangga pada gigi 22 dan 24 dibuat disain kerangka logam anterior yang memerlukan faktor estetik sehingga logam tidak terlihat. Disain terdiri dari rest singulum pada gigi 22 dan rest oklusal pada bagian mesial gigi 24 untuk mencegah berpindahnya GTJ adesif ke arah gingiva pada waktu berfungsi, peliputan proksimal, akhiran preparasi berbentuk chamfer supragingival dan bagian insisal kerangka logam minimal $2 \mathrm{~mm}$ di bawah garis insisal untuk mencegah bayangan abu-abu pada gigi sandaran. ${ }^{7,8}$

Pada kasus pasien 2 yang kehilangan gigi 24 , pasien tidak menghendaki pembuatan gigitiruan lepasan dan juga tidak menghendaki pengasahan gigi yang banyak. Oleh karena itu dibuatkan GTJ adesif posterior untuk menggantikan kehilangan gigi 24 , sedangkan gigi penyangga pada gigi 23 dan 25 dengan disain rest singulum pada gigi 23 untuk mencegah berpindahnya GTJ adesif ke arah gingiva, dan rest oklusal ditempatkan pada bagian mesial gigi 25 , peliputan proksimal melalui titik kontak diperluas ke arah bukal untuk mencegah perpindahan ke lateral dan logam yang terlihat ditutupi bahan estetik, akhiran preparasi berbentuk chamfer supragingival. ${ }^{3}$

Kontrol pasien dan evaluasi GTJ adesif perlu dilakukan setelah GTJ adesif dilekatkan. Pada saat kunjungan pasien, pemeriksaan dan evaluasi yang dilakukan meliputi pemeriksaan keluhan pasien, integritas pelekatan GTJ, pemeriksaan adaptasi pinggiran GTJ, permukaan GTJ adesif, estetik, oklusi dan artikulasi, evaluasi terhadap kesehatan dan respon jaringan sekitarnya. ${ }^{2}$

Disimpulkan bahwa pada pembuatan GTJ adesif diperlukan seleksi kasus yang tepat, keakuratan dan retensi yang baik dari kerangka logam, dan pengetsaan yang optimal. Keuntungan yang utama dari GTJ adesif adalah konservasi 
struktur gigi yang ada. Teknik yang dipakai dapat sangat menguntungkan tetapi harus dilakukan dengan hati-hati. Motivasi dan kemampuan pasien bekerjasama untuk memelihara serta menjaga kebersihan mulut secara intensif ikut menunjang keberhasilan perawatan yang maksimal.

\section{DAFTAR PUSTAKA}

1. Martanto P. Teori dan praktek ilmu mahkota dan jembatan. Jilid I. Bandung: Penerbit Alumni; 1981. p. 5.

2. Sophia DM, Firman D, Adenan A. Jembatan adhesif dengan retensi teknik anyaman pada bagian pelekatan kerangka logam. Dalam: Dari Bandung untuk khazanah ilmu kedokteran gigi. Kumpulan makalah temu ilmiah kedokteran gigi (TIKEGI) 2000. Bandung: Lembaga Studi Kesehatan Indonesia; 2000. p. 31-9.

3. Rosenstiel SF, Land MF, Fujimoto J. Contemporary fixed prosthodontics. $4^{\text {th }}$ Ed. Missouri: Mosby Elsevier; 2006. p. 805-24.

4. Prajitno HR. Ilmu geligi tiruan jembatan. Cetakan II. Jakarta: Penerbit Buku Kedokteran EGC; 1994. p. 147-53.

5. Ibbetson R. Clinical considerations for adhesive bridgework. Dental Update 2004; 31: 254-65.

6. Simon JF, Gartrell RG, Grogono A. Improved retention of acid etched fixed partial dentures: A longitudinal study. J Prosthet Dent 1992; 68: 611-5.

7. Dale BG, Aschheim KW. Esthetic dentistry a clinical approach to techniques and materials. Philadelphia: Lea \& Febiger; 1993. p. 151-62.

8. O’Sullivan M. Fixed prosthodontics in dental practice. London: Quintessence Publishing Co. Ltd; 2005. p. 12937. 